\title{
Mechanism of impaired nitric oxide synthase activity in skeletal muscle of streptozotocin-induced diabetic rats
}

\section{Perreault, L. Dombrowski, A. Marette}

Department of Anatomy and Physiology and Lipid Research Unit, Laval University Hospital Research Center, Ste-Foy, Québec, Canada

\section{Abstract}

Aims/hypothesis. The aims of our study were to investigate whether nitric oxide synthase (NOS) activity is impaired in skeletal muscle of insulin-deficient [Type I (insulin-dependent)] diabetic rats and if the case, to determine the mechanism of NOS dysregulation in this disorder.

Methods. Rats were rendered diabetic by streptozotocin injection $(65 \mathrm{mg} / \mathrm{kg}$, i.v.) and NOS activity and expression in gastrocnemius muscles were studied 1, 2,3 or 4 weeks after diabetes induction.

Results. The diabetic state was associated with a progressive reduction (down to $42 \%$ of control values after 4 weeks) in muscle NOS activity compared with control rats. Using reverse transcriptase-polymerase chain reaction, we could not detect statistically significant changes in the expression of either neuronal NOS $(n N O S)$ or endothelial NOS $(e N O S)$ mRNAs in diabetic muscle. The contents of $n \mathrm{NOS}$ and $e \mathrm{NOS}$ protein were, however, progressively reduced in muscle homogenates of diabetic rats and these alterations were prevented by insulin treatment. Subcellular fractionation of skeletal muscle showed that both $n$ NOS and $e$ NOS proteins are mainly localised to the plasma membrane with lower abundance in T-tubules and not detectable in sarcoplasmic reticulum-enriched fractions. After 1 week of diabetes, $e$ NOS protein content was decreased only in the plasma membrane whereas $n$ NOS protein abundance was not affected at this time. Neither the expression nor the interaction of caveolin-1 and caveolin-3 with NOS enzymes was found to be altered in muscle of diabetic rats.

Conclusion/interpretation. These results show that skeletal muscle NOS activity is impaired during the progression of insulin-deficient diabetes and reduced NOS activity is associated with a decreased abundance of both $n$ NOS and $e$ NOS proteins, which appears to involve post-transcriptional mechanisms. [Diabetologia (2000) 43: 427-437]

Keywords $e$ NOS, $n$ NOS, caveolins, plasma membrane, transverse tubules.
Received: 7 October 1999 and in revised form: 23 December 1999

Corresponding author: Dr A. Marette, Department of Physiology \& Lipid Research Unit, Laval University Hospital Research Center, 2705, Laurier Bld, Ste-Foy, (Québec), Canada, G1V 4G2

Abbreviations: CSM, Crude surface membrane; DHPr, dihydropyridine receptor; GAPDH, glyceraldehyde phosphate dehydrogenase; FMN, flavin mononucleotide; L-NAME, $N^{G}$-nitro-L-arginine methyl ester; NO, nitric oxide; NOS, nitric oxide synthase; $e$ NOS, endothelial nitric oxide; iNOS, inducible nitric oxide; $n$ NOS, neuronal nitric oxide; $\mathrm{SR}$, sarcoplasmic reticulum; STZ, streptozotocin; PVDF, polyvinyldene difluoride.
Type I (insulin-dependent) diabetes mellitus is characterised by pronounced insulin resistance for glucose disposal in skeletal muscle $[1,2]$. This metabolic impairment is at least in part related to a post-insulin signalling defect in the expression and translocation of GLUT4 glucose transporters to the muscle cell surface [3-5]. The lack of insulin action on glucose metabolism in muscle of people with Type I diabetes could also be explained by an impaired vasodilatory effect of insulin on the muscle vasculature [2], although this impairment has not been confirmed in a more recent study [1]. Several studies have shown that endothelium-dependent relaxation is altered in 
experimental diabetes [6-8]. Endothelial dysfunction in diabetes seems to be subjected to regional variations. Indeed, it was previously reported that bradykinin-mediated vasodilatation is decreased in the hindquarters vascular bed of streptozotocin (STZ)-rats but not in renal and mesenteric beds [9]. The mechanisms of decreased bradykinin-mediated vasodilatory responses in the hindlimb muscle beds of STZ-rats are not fully understood; however, an impaired nitric oxide (NO) generation or bioactivity could be involved [7].

Previous studies looking at vascular nitric oxide (NO) synthesis or action in insulin-deficient diabetes have led to conflicting results. Enhanced, unaltered, or decreased NO-mediated, endothelium-dependent vasodilatation have been reported [7] and this apparent lack of consistency could be explained by the type of artery or vasodilator agent examined or both as well as the duration and severity of the diabetic state. Most studies are nevertheless consistent with altered NO-dependent responses when the diabetic state is well established [7]. What is not clear is whether an altered NO synthesis is responsible for endothelial dysfunction in diabetes. Impaired NO bioactivity could arise not only from reduced production but also from increased destruction of the released NO by chemical interactions with reactive oxygen species or advanced glycation end-products, or resistance of vascular smooth muscle cells to normal endothelium NO production $[6,10]$.

Skeletal muscle expresses all isoforms of the NO synthase (NOS) family, which comprises the $\mathrm{Ca}^{2+}$ calmodulin-dependent neuronal-type ( $n$ NOS, also known as NOS I) and endothelial-type ( $e$ NOS, also known as NOS III) forms, as well as an inducible, relatively $\mathrm{Ca}^{2+}$-independent, form known as $i$ NOS (or NOS II). Both $e$ NOS and $n$ NOS are constitutively expressed in rat skeletal muscle whereas $i$ NOS is only expressed to detectable concentrations in pathological conditions including endotoxaemia and muscle injury $[11,12]$. The role of NOS enzymes in skeletal muscle is still not fully understood. Endothelium $e$ NOS is clearly involved in vascular remodelling and plays an important part in haemodynamic regulation of muscle vascular beds. On the other hand, there is growing evidence that NOS enzymes are involved in the modulation of several other muscle functions including contractile, neural, and metabolic functions [13]. Our laboratory has been particularly interested in the role of NOS enzymes in modulating glucose metabolism in skeletal muscle. Endothelial cell $e$ NOS is thought to play a critical part in modulating muscle glucose utilisation by mediating the haemodynamic action of insulin on the muscle vasculature, thus providing an increased supply of glucose and insulin to the muscle fibres [14-16]. This concept has been recently supported by our observation that the NOS inhibitor $N^{G}$-nitro-L-arginine methyl ester
(L-NAME) greatly reduces insulin-stimulated glucose uptake in muscle when given to rats in vivo during an hyperinsulinaemic-euglycaemic clamp [17].

It is not known whether muscle NOS activity is altered in insulin-deficient diabetes. A lack of NOS activity in diabetic muscle could explain the reported defect in NO vascular bioactivity and contribute to the impaired insulin-stimulated glucose uptake in diabetes. An abnormal NO synthesis at the neuromuscular junctions as well as in muscle cells could also be involved in the development of contractile dysfunction (neuromyopathy) in diabetes $[18,19]$. The goal of our study was therefore to test the hypothesis that muscle NOS activity is reduced in insulin-deficient diabetes and if the case, to determine the mechanism of NOS dysregulation in this disorder.

\section{Materials and methods}

Materials. We purchased NADPH, flavin mononucleotid (FMN), flavin adenine dinucleotide (FAD), calmodulin, streptozotocin (STZ), BH4 and octylglucoside from Sigma (St. Louis, Mo., USA). L-NAME from Alexis (San Diego, Calif., USA), $\left[{ }^{3} \mathrm{H}\right]$-L-arginine from Amersham (Oakville, Ont., Canada), Dowex AG50W-X8 from Bio-Rad (Mississauga, Ont., Canada). Protein A Sepharose beads were obtained from Amersham Pharmacia Biotech (Baie d'Urfé, Q., Canada). Monoclonal ( $e$ NOS and caveolin-3) and polyclonal ( $n$ NOS and caveolin-1) antibodies were obtained from Transduction Laboratories (Lexington, Ky., USA). The monoclonal antibody IIF7 generated against the $\alpha 1$-dihydropyridine receptor (DHPr) was kindly supplied by Dr K. Campbell (University of Iowa, Iowacity, Iowa, USA). The monoclonal antibody against the $\alpha 1-\mathrm{Na} / \mathrm{K}-\mathrm{ATP}$ ase was a kind gift from Dr K. Sweadner (Massachusetts General Hospital, Boston, Mass., USA).

Animals. This study was approved by the Animal care and handling committee of Laval University. Male Sprague-Dawley rats weighing 240-260 g (Charles River, Montréal, Que., Canada) were randomly assigned to STZ-diabetic or control groups, housed in individual cages, maintained on a 12-h dark and light schedule and fed according to appetite with Purina rat chow. Animals were anaesthetised with ketamine-xylazine (80 and $10 \mathrm{mg} / \mathrm{kg}$ i.p.) and STZ (65 mg/kg i.v.) or citrate buffer was injected. After STZ injection at intervals of $1,2,3$ or 4 weeks, diabetic animals and their age-matched control animals were killed by decapitation, blood was collected, and muscles (gastrocnemius and quadriceps) were removed and immediately frozen in liquid nitrogen and stored at $-80^{\circ} \mathrm{C}$ until further analyses.

Additional rats were used to test the effect of insulin treatment on diabetic animals. Insulin [2.4 $\mathrm{U}$ regular and $3.6 \mathrm{U}$ ultra-lente (morning) and 3.2 $\mathrm{U}$ regular and $3.6 \mathrm{U}$ ultra-lente (night), s.c.] was injected 1 day after STZ injection and was continued for 2 weeks. Rats were then killed by decapitation and hindlimb muscles were removed and immediately frozen in liquid nitrogen and stored at $-80^{\circ} \mathrm{C}$.

Skeletal muscle fractionation. Muscles were cleaned of extraneous tissues and homogenised in $5 \mathrm{v}$ of homogenisation buffer containing $25 \mathrm{mmol} / \mathrm{l}$ TRIS-HCL (pH 7.4), 1 mmol/l EDTA, protease inhibitors $[1 \mathrm{mmol} / \mathrm{l}$ pepstatin $\mathrm{A}, 10 \mathrm{mmol} / \mathrm{l} \mathrm{E} 64$ and $1 \mathrm{mmol} / \mathrm{l}$ leupeptin, $100 \mu \mathrm{g} / \mathrm{ml}$ phenylmethylsulphonyl fluoride 
(PMSF) $]$ and then centrifuged for $10 \mathrm{~min}$ at $1200 \times g$ to remove non-homogenised material (crude homogenate). In some experiments, the two components of the muscle cell surface, namely the plasma membrane and transverse tubules, were purified by differential centrifugation as described previously [20]. This crude surface membrane fraction (CSM) was further fractionated on discontinuous sucrose gradients $(25 \%, 32 \%$ and $35 \%$, w/w) to yield plasma membrane and transverse tubule vesicles. Plasma membranes are recovered at the buffer/ $25 \%$ sucrose interphase whereas T-tubules band at the $32 \% /$ $35 \%$ interphase on the gradient. The membrane fractions have been extensively characterised by immunologic and enzymatic markers $[4,20]$. Protein concentrations of the membrane fractions were determined by the bicinchoninic acid method using BSA as the standard.

Nitric oxide synthase activity. Nitric oxide synthase activity was quantified by the conversion of $\left[{ }^{3} \mathrm{H}\right]$-L-arginine to $\left[{ }^{3} \mathrm{H}\right]$-L-citrulline, with minor modifications $[12,17]$. Briefly, aliquots of the homogenates (100-200 $\mu \mathrm{g}$ proteins) were incubated in $50 \mathrm{mmol} / \mathrm{l} \mathrm{HEPES}(\mathrm{pH} 7.4)$ with $24 \mu \mathrm{mol} / \mathrm{l}\left[{ }^{3} \mathrm{H}\right]$-L-arginine $(0.1 \mu \mathrm{Ci} /$ tube $), \quad 120 \mu \mathrm{mol} / \mathrm{l} \quad \mathrm{NADPH}, 60 \mathrm{mmol} / \mathrm{l} \quad$ L-valine, $12 \mathrm{mmol} / \mathrm{l}$ L-citrulline, $1.2 \mathrm{mmol} / 1 \mathrm{MgCl}_{2}, 0.2 \mathrm{mmol} / \mathrm{CaCl}_{2}$, $10 \mu \mathrm{g} / \mathrm{ml}$ calmodulin, $3 \mu \mathrm{mol} / \mathrm{l} \mathrm{BH} 4,1 \mu \mathrm{mol} / \mathrm{l}$ flavin adenine dinucleotide (FAD) and $1 \mu \mathrm{mol} / \mathrm{l}$ flavin mononucleotide (FMN). The reaction was carried out for $1 \mathrm{~h}$ at $37^{\circ} \mathrm{C}$ with or without L-NAME $(2 \mathrm{mmol} / \mathrm{l})$ and terminated by adding $2 \mathrm{ml}$ of icecold buffer (20 mmol/l HEPES pH 5.5, 2 mmol/l EDTA). Samples were applied to 1-ml columns of Dowex AG50W-X8 ( $\mathrm{Na}^{+}$form), which were eluted with $2 \mathrm{ml}$ of water. The $\left[{ }^{3} \mathrm{H}\right]-\mathrm{L}-$ citrulline was quantified by liquid scintillation spectroscopy (Wallac 1409 counter, Turku, Finland) of 4.0-ml flow through.

Immunoprecipitation. Immunoprecipitation of caveolin-1 and caveolin-3 was done as described previously with minor modifications [21]. The CSM membranes fractions $(200 \mu \mathrm{g})$ were incubated $1 \mathrm{~h}$ at $4{ }^{\circ} \mathrm{C}$ in a buffer containing $60 \mathrm{mmol} / 1$ octylglucoside, $50 \mathrm{mmol} / \mathrm{l} \mathrm{TRIS}-\mathrm{HCl}$ (pH 7.4), $125 \mathrm{mmol} / \mathrm{l} \mathrm{NaCl}, 2 \mathrm{mmol} / 1$ dithiothreitol, $100 \mu \mathrm{mol} / \mathrm{l}$ EGTA and protease inhibitors. Samples were first incubated with caveolin-1 antibodies $(4 \mu \mathrm{g} / \mathrm{ml})$ for $1 \mathrm{~h}$ at $4{ }^{\circ} \mathrm{C}$. Protein A Sepharose beads $(50 \mu \mathrm{l}$ of a $50 \%$ slurry) were added to the supernatant for a further 1-h incubation at $4{ }^{\circ} \mathrm{C}$. Bound immune complexes were pelleted by centrifugation, washed three times with octylglucoside buffer and then once with $50 \mathrm{mmol} / \mathrm{l}$ TRIS-HCl (pH 7.4), $150 \mathrm{mmol} / \mathrm{l} \mathrm{NaCl}$. The supernatant fraction was then incubated with caveolin-3 antibodies $(4 \mu \mathrm{g} / \mathrm{ml})$ for immunoprecipitation of caveolin-3 as described above for caveolin-1. The immunoprecipitates were eluted by boiling in Laemmli sample buffer before SDSPAGE and western blot analysis as described below.

Western blot analysis. Muscle homogenates $(150 \mu \mathrm{g})$ or purified membrane fractions $(10-20 \mu \mathrm{g})$ were subjected to sodium dodecyl sulphate polyacrylamide gel electrophoresis (SDSPAGE) as described by Laemmli [22], and electrophoretically transferred $(100 \mathrm{~V})$ to a polyvinyldene difluoride (PVDF) filter membrane for $2 \mathrm{~h}$. Immunoblotting was done as described previously [20]. Briefly, PVDF membranes were incubated for $1 \mathrm{~h}$ at room temperature with buffer I $(50 \mathrm{mmol} / \mathrm{l}$ TRIS- $\mathrm{HCl}$ [pH 7.4], $150 \mathrm{mmol} / \mathrm{l} \mathrm{NaCl}, 0.04 \%$ NP-40, $0.02 \%$ Tween 20) containing $5 \%$ non-fat milk, followed by overnight incubation at $4{ }^{\circ} \mathrm{C}$ with primary antibodies. Dilutions of antibodies were: $n$ NOS 1:250, eNOS 1:500, caveolin-3 1:7500, caveolin-1 1:4000. Washing of PVDF membranes for $45 \mathrm{~min}$, was followed by $1 \mathrm{~h}$ incubation with either anti-mouse or anti-rabbit immunoglobulin G (Amersham, Oakville, Ont., Canada) conjugated to horseradish peroxidase in buffer I containing $5 \%$ non-fat milk. After PVDF membranes were washed for $45 \mathrm{~min}$ in buffer I the immunoreactive bands were detected by the enhanced chemiluminescence method (Renaissance ECL kit, NEN Life Science, Boston, Mass., USA). Autoradiographs were analysed by laser scanning densitometry using a tabletop Agfa scanner (Arcus II, Etobicoke, Ont., Canada) and quantified with the NIH Image program (zippy.nmh. nih.gov). Muscle standards were run on every gel for comparison of samples from different immunoblots. Values are expressed as densitometric units relative to the muscle standards run on every gel.

Extraction of RNA and RT-PCR. Total cellular RNA was isolated using guanidium thiocyanate-phenol-chloroform extraction with the TRIzol Reagent based on a method developed previously [23]. Synthesis of cDNA and amplification were done with 200 units of Moloney murine leukaemia virus reverse transcriptase (Gibco BRL, Burlington, Ont., Canada), using $1 \mu \mathrm{g}$ of total RNA in $20 \mu \mathrm{l}$ of reverse transcriptase buffer (50 mmol/l TRIS-HCl, pH 8.3, 75 mmol/1 KCl, 3 mmol/1 $\mathrm{MgCl}_{2}$ and $10 \mathrm{mmol} / \mathrm{l}$ dithiothreitol (DTT) containing $1 \mathrm{mmol} / \mathrm{l} \mathrm{deox-}$ yribonucleoside triphosphate (dNTP) and $8 \mathrm{pmol}$ of $e$ NOS, $n$ NOS or glyceraldehyde phosphate dehydrogenase (GAP$\mathrm{DH})$ antisense primer. The reaction was carried out at $42^{\circ} \mathrm{C}$ for $1 \mathrm{~h}$ and the enzyme was then denaturated at $95^{\circ} \mathrm{C}$ for $10 \mathrm{~min}$. Samples were then supplemented with $30 \mu \mathrm{l}$ of buffer containing TRIS $\mathrm{pH} 8.3, \mathrm{MgCl}_{2}, \mathrm{KCl}$ and sense primer to obtain a final concentration of $10 \mathrm{mmol} / \mathrm{l} \mathrm{TRIS}, 50 \mathrm{mmol} / \mathrm{l} \mathrm{KCl}$ and $2 \mathrm{mmol} / 1 \mathrm{MgCl}_{2}$ (for GAPDH and $n \mathrm{NOS}$ ) or $1.5 \mathrm{mmol} / \mathrm{l}$ $\mathrm{MgCl}_{2}$ (for $e \mathrm{NOS}$ ), 8 pmol of $e \mathrm{NOS}, n \mathrm{NOS}$ and GAPDH sense primer. The cDNAs were denatured for 5 min at $94^{\circ} \mathrm{C}$, cooled to $72^{\circ} \mathrm{C}$ and then 1 unit of Thermophilus aquaticus DNA polymerase (Boehringer Mannheim, Mississauga, Ont., Canada) was added to each sample. Amplification was by 30 cycles of temperature cycler (DNA Thermal Cycler, Perkin-Elmer, Mississauga, Ont., Canada). Sequences of the antisense and sense oligonucleotides (based on rat NOSs and GAPDH) were as follows; $e$ NOS: 5 '-CAGGCTGCAGTCCTTTGATC$3^{\prime}$ and 5'-TACGGAGCAGCAAATCCAC-3', nNOS: 5'TCCAGCACCTCCACC-ATTGTG-3' and $5^{\prime}$-GTGGGGGATGACGTCAACATC-3', GAPDH: 5'-AGATCCACAACGGA-TACATT-3' and 5'-TCCCTCAAGATTGTCAGCAA-3'. The expected sizes of amplification products were 331 base pairs for GAPDH, 806 base pairs for $e$ NOS and 622 base pairs for $n$ NOS. Amplification products were run in $8 \%$ acrylamide gels, stained in ethidium bromide, and fluorescence associated with DNA bands was analysed by laser scanning densitometry as described above. In preliminary experiments with various amounts of muscle RNA, it was verified that $e$ NOS, $n$ NOS, and GAPDH are amplified linearly using the above RT-PCR conditions.

Analytical methods. Plasma glucose concentrations were measured enzymatically by the glucose oxidase method using a kit from Sigma (St. Louis, Mo., USA). Plasma insulin concentrations were assessed by RIA with a rat insulin specific kit from Linco (St. Charles, Mo., USA), using rat insulin as standard.

Statistical analysis. Values are means \pm SEM. Multiple comparisons were made by analysis of variance followed by Fisher's PLSD post-hoc test for individual differences. Student's $t$ test for unpaired comparisons was used when only two groups were compared. The level of significance was $p$ less than 0.05 . 
Table 1. Glycaemia and insulinaemia of control and STZ-diabetic rats

\begin{tabular}{lcl}
\hline Group & $\begin{array}{l}\text { Glycaemia } \\
(\mathrm{mmol} / \mathrm{l})\end{array}$ & $\begin{array}{l}\text { Insulinaemia } \\
(\mathrm{nmol} / \mathrm{l})\end{array}$ \\
\hline Control & $7.63 \pm 0.23^{\mathrm{a}}$ & $0.725 \pm 0.08^{\mathrm{a}}$ \\
STZ 1 & $19.13 \pm 1.92^{\mathrm{b}}$ & $0.408 \pm 0.07^{\mathrm{b}}$ \\
STZ 2 & $20.13 \pm 1.79^{\mathrm{b}}$ & $0.193 \pm 0.01^{\mathrm{b}}$ \\
STZ 3 & $27.19 \pm 0.13^{\mathrm{c}}$ & $0.530 \pm 0.17^{\mathrm{a}, \mathrm{b}}$ \\
STZ 4 & $26.34 \pm 0.59^{\mathrm{c}}$ & $0.380 \pm 0.08^{\mathrm{b}}$ \\
STZ 2 + Insulin & $6.30 \pm 1.10$ & $1.090 \pm 0.87$
\end{tabular}

Rats were rendered diabetic by STZ injection and plasma (postprandial state) was collected one (STZ 1), two (STZ 2), three (STZ 3) or four (STZ 4) weeks after diabetes induction. STZ 2 + insulin: 2-week STZ-diabetic rats that were treated with insulin. Values are means \pm SEM of 5-10 rats. Groups not sharing a common superscript $(\mathrm{a}, \mathrm{b}$ or $\mathrm{c})$ are different at $p<0.05$. Plasma glucose and insulin values from 2-week STZdiabetic rats treated with insulin (STZ $2+$ insulin) were not different from values of control animals

\section{Results}

Plasma concentrations of glucose and insulin of control and STZ-rats are shown in Table 1. Glucose and insulin values of age-matched control rats (1-4 weeks) were not different and were therefore consolidated. As expected, hyperglycaemia and hypoinsulinaemia were observed 1 week after induction of diabetes with STZ and were maintained throughout the study period. Insulin concentration was somewhat increased in 3-week STZ-rats but these values were still far below normal when considering the pronounced hyperglycaemia of these animals. Insulin treatment of 2-week diabetic rats returned both glycaemia and insulinaemia to normal.

It should be noted that muscle NOS activity and expression of NOS enzymes were not different between control rats that were age-matched to the STZ-treated animals for the duration of the diabetic state (1-4 weeks). Values for control rats at all weeks were therefore consolidated in Figs. 1-3. The NOS activity in gastrocnemius muscle decreased during the progression of diabetes (Fig. 1). The diabetic state was associated with a progressive reduction in muscle NOS activity (1 week: $60.5 \%, 2$ weeks: $41.7 \%$, 3 weeks: $34.8 \%$ and 4 weeks: $42.1 \%$ of control NOS activity). Furthermore, the decreased NOS activity was observed when the enzyme was assayed in the presence of $\mathrm{Ca}^{2+}$, thus suggesting that the activity of the $\mathrm{Ca}^{2+}$-dependent $n$ NOS or $e$ NOS enzymes or both were affected.

We next investigated the mechanisms responsible for impaired NOS activity in skeletal muscle of STZdiabetic rats. First we evaluated the effect of STZ-diabetes on the expression of $e$ NOS and $n$ NOS mRNA expression, as assessed by RT-PCR. A representative experiment is depicted in Figure 2 and results from several animals were quantified by scan-

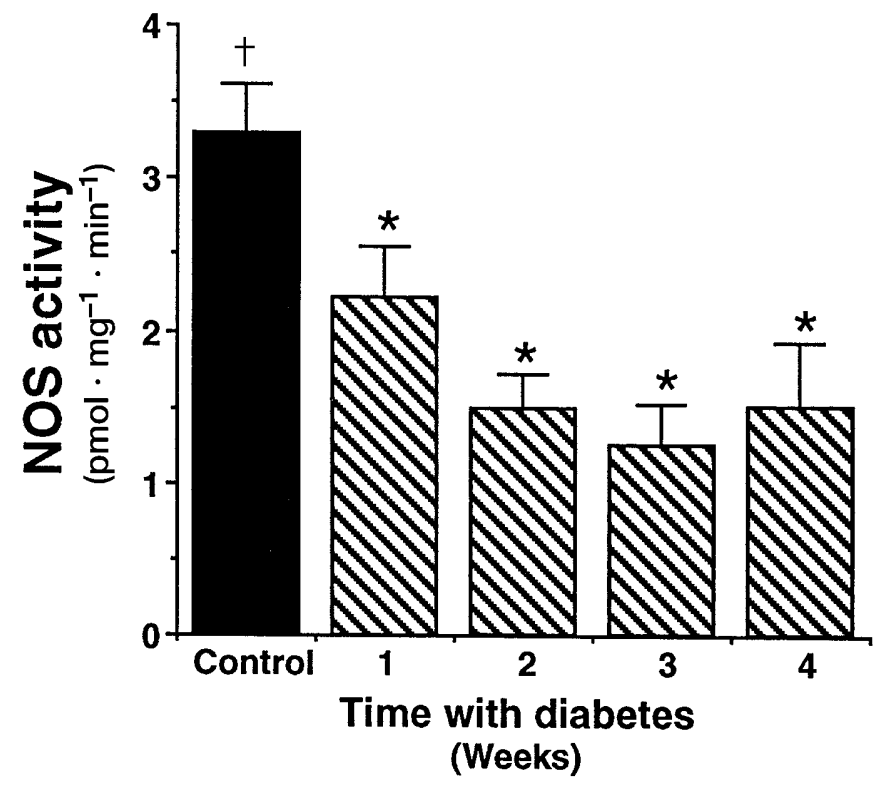

Fig.1. Effects of STZ-diabetes on NOS activity in gastrocnemius muscle. Rats were rendered diabetic by injection of STZ and studied 1, 2, 3 or 4 weeks after diabetes induction. NOS activity was determined using equivalent muscle extracts $(200 \mu \mathrm{g})$ from control or diabetic rats (see Methods). Results are means \pm SEM of five to eight individual experiments. Age-matched control rats were analysed at each time point (1-4 weeks) to verify the possible influence of ageing in itself on muscle NOS activity. No differences in NOS activity were observed between control rats at 1,2, 3 or 4 weeks post-treatment and all control data were therefore consolidated. Bars not sharing a common symbol are different at $p<0.05$

ning densitometry, normalised for GAPDH transcript abundance in the same samples, and the mean data are presented in Table 2. The content of $e$ NOS or $n$ NOS mRNA was not significantly affected by the diabetic state, even after 4 weeks of severe hyperglycaemia and relative insulin deficiency.

We then tested whether skeletal muscle $e$ NOS or $n$ NOS protein contents or both were affected by STZ-diabetes. Equivalent amounts of muscle proteins were resolved on SDS-PAGE and immunoblotting was done using $e$ NOS or $n$ NOS specific antibodies (Fig. 3). Both proteins migrated as a single band of about $140000 \mathrm{M}_{\mathrm{r}}$ for $e$ NOS and about $155000 \mathrm{M}_{\mathrm{r}}$ for $n$ NOS (Fig. 3). Immunoreactivity of $e$ NOS and $n$ NOS was quantified by scanning densitometry and the mean data are presented (Fig. 3). In great contrast to the lack of effect on transcript expression, both $e$ NOS and $n$ NOS protein concentrations were greatly affected by the diabetic state. The abundance of both enzymes progressively decreased in muscle of STZrats (Fig. 3). Impaired $e$ NOS protein expression was already detectable 1 week after induction of diabetes and was reduced to about $10 \%$ of control values after 4 weeks. The abundance of $n$ NOS protein was significantly decreased to $25 \%$ of controls in muscle of 2 week STZ-rats but did not further decline with the 


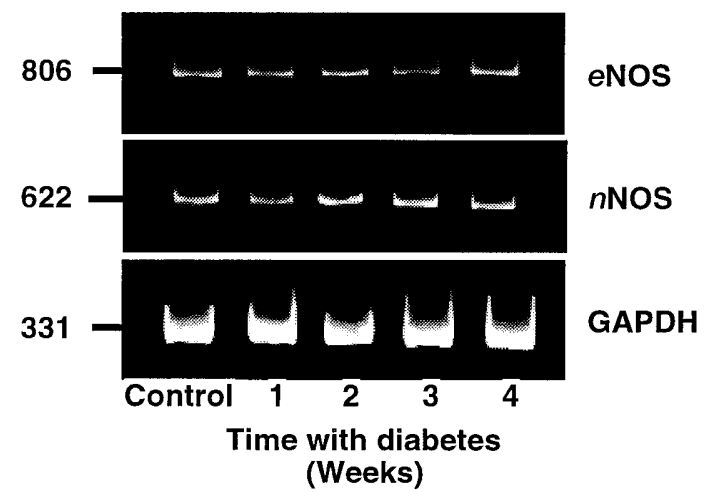

Fig. 2. Effects of STZ-diabetes on $e$ NOS and $n$ NOS mRNA expression in gastrocnemius muscle. Rats were same as in Fig. 1. RNA was isolated from 50-100 mg of muscle tissue and $e$ NOS, $n$ NOS and GAPDH mRNAs were measured by RTPCR as described in Methods. Amplified DNA products were separated on polyacrylamide gels and made visible with ethidium bromide. The figure shows a representative gel from four to eight rats. Mean \pm SEM of several rats are shown in Table 2

Table 2. Expression of $e$ NOS and $n$ NOS mRNAs in skeletal muscle of control and STZ-diabetic rats

\begin{tabular}{lll}
\hline & $\begin{array}{l}e \text { NOS/GAPDH } \\
\text { relative densitometric } \\
\text { units }\end{array}$ & $\begin{array}{l}n \text { NOS/GAPDH } \\
\text { relative densitometric } \\
\text { units }\end{array}$ \\
\hline Control & $0.143 \pm 0.027$ & $0.076 \pm 0.014$ \\
STZ 1 & $0.206 \pm 0.029$ & $0.061 \pm 0.024$ \\
STZ 2 & $0.143 \pm 0.038$ & $0.107 \pm 0.029$ \\
STZ 3 & $0.087 \pm 0.041$ & $0.082 \pm 0.046$ \\
STZ 4 & $0.186 \pm 0.022$ & $0.096 \pm 0.054$ \\
\hline
\end{tabular}

Rats were rendered diabetic by STZ injection and gastrocnaemius muscles were removed 1,2,3 or 4 weeks after diabetes induction. RNA was isolated from $50-100 \mathrm{mg}$ of muscle and $e$ NOS, $n$ NOS and GAPDH transcripts were measured by RT-PCR. Values are means \pm SEM of 5-8 rats. No significant differences were observed between control and STZ-rats

duration of the disease. Importantly, insulin treatment of 2-week STZ-rats prevented the reduction of muscle $e$ NOS and $n$ NOS protein expression (Fig.3), indicating that these impairments were not caused by STZ treatment in itself.

Both $e$ NOS and $n$ NOS have been shown to be localised at or near the plasma membrane of skeletal muscle and endothelial cells [12, 13, 24-27]. It was therefore of interest to more precisely localise the site of impaired NOS expression in muscle of diabetic animals, especially early (1 week) in the duration of the disease where expression of NOS enzymes was not yet found to be greatly reduced in muscle homogenates. Using a well-established subcellular fractionation procedure developed in our laboratory [20], we isolated membrane fractions enriched in either crude surface membranes (CSM), plasma membranes, transverse tubules (TT), triads [where transverse tubules are in apposition to the sarcoplasmic reticulum (SR)] and SR. The distribution of $e$ NOS
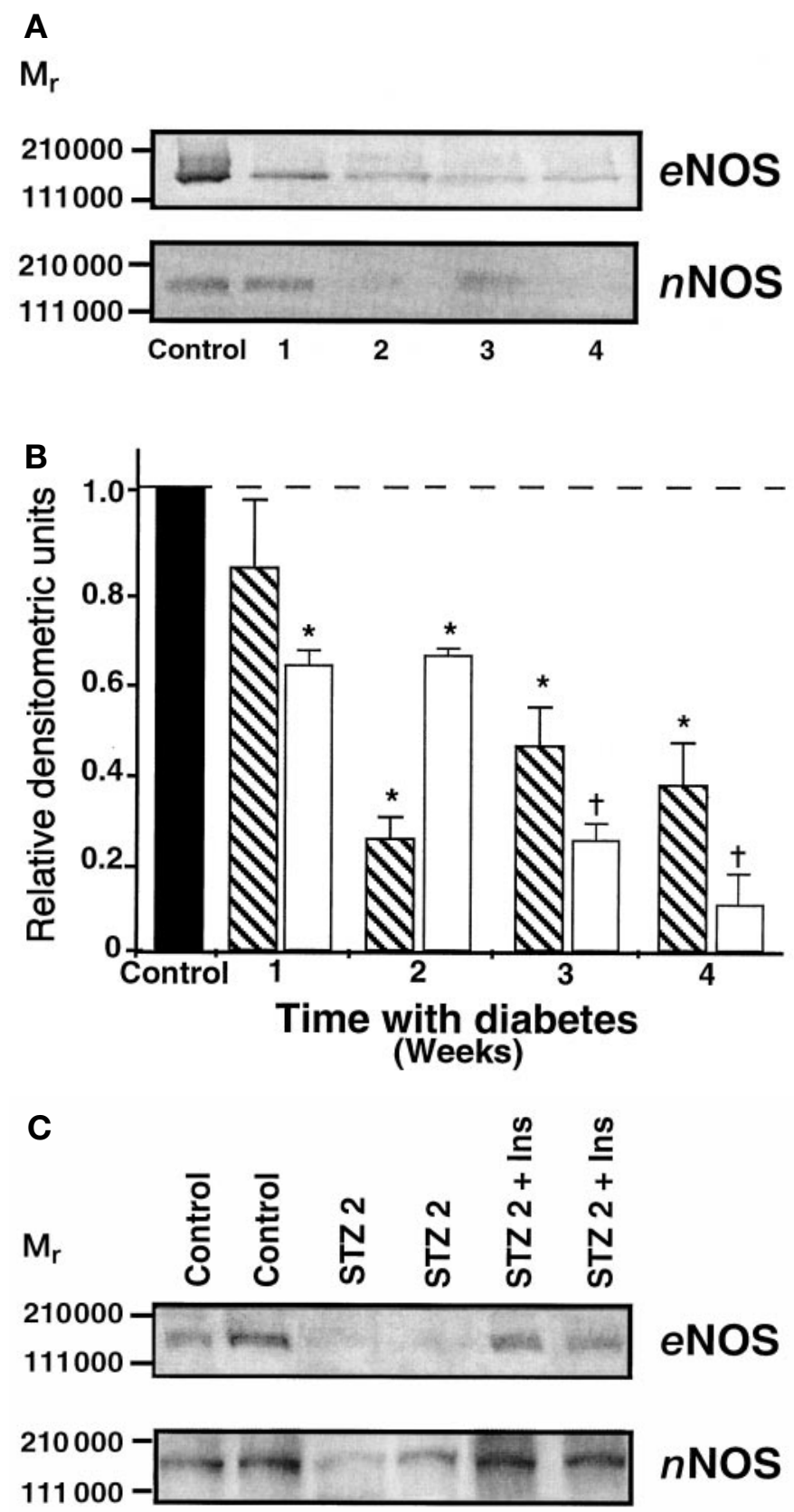

Fig. 3 A-C. Effects of STZ-diabetes on $e$ NOS and $n$ NOS protein contents in gastrocnemius muscle. Rats were same as in Fig. 1 except in $(\mathbf{C})$ where STZ-rats were treated with insulin for 2 weeks. Muscle extracts $(150 \mu \mathrm{g})$ were subjected to SDSPAGE and analysed by western blotting using $e$ NOS-specific or $n$ NOS-specific antibodies. (A) Representative immunoblots. (B) Results are means \pm SEM of five to ten independent experiments with tissues from different animals. Data are expressed as relative changes compared with the control values for each NOS isoform. The symbol * indicates a significant difference $(p<0.05)$ vs control values. The symbol $†$ indicates a significant difference $(p<0.05)$ vs 2 week-old values. (C) Representative immunoblots showing the prevention of $e$ NOS and $n$ NOS down-regulation by insulin treatment of STZ-diabetic rats for 2 weeks (STZ2 + Ins). Similar data were obtained with four different rats in each group. Molecular weight standards (in $\mathrm{M}_{\mathrm{r}}$ ) are shown on the left. $\mathbf{N}, n \mathrm{NOS} ; \square, e \mathrm{NOS}$ 


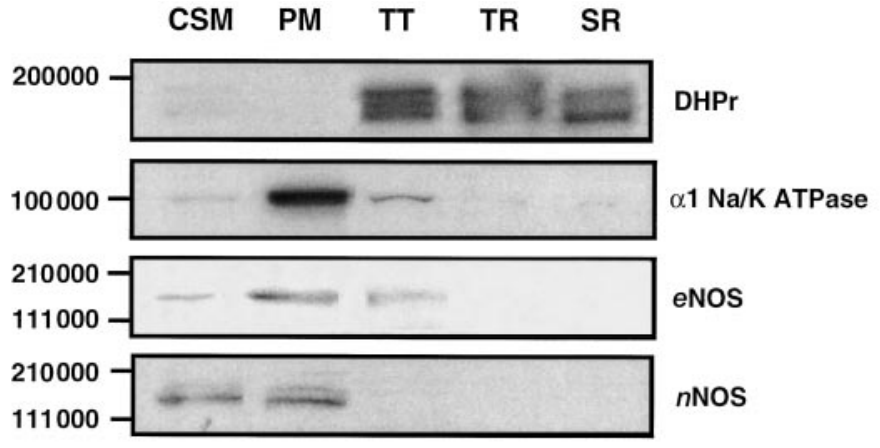

Fig. 4. Membrane distribution of the dihydropyridine receptor (DHPr), $\alpha 1-\mathrm{Na}-\mathrm{K}-\mathrm{ATPase}, e$ NOS and $n$ NOS proteins in crude surface membranes (CSM), plasma membranes (PM), transverse tubules (TT), triads (TR) and sarcoplasmic reticulum (SR) isolated from muscles of control rats. Membrane proteins (10-20 $\mu \mathrm{g}$ ) were isolated and purified as described in Methods and used for western blot analysis with $\alpha 1-\mathrm{Na}-\mathrm{K}-\mathrm{ATP}$ ase (McK-1) monoclonal antibody (1:200), DHPr monoclonal antibody (1:200 000), eNOS monoclonal antibody (1:500) and $n$ NOS polyclonal antibody (1:250). ECL detection of reactive bands was carried out. The figure depicts a representative gel from three different subcellular fractionation experiments with different rats. Molecular weight standards (in $\mathbf{M}_{r}$ ) are shown on the left

and $n$ NOS enzymes and of typical markers of the plasma membrane and TT in the purified fractions are shown in Figure 4. As expected, the $\alpha 1$-subunit of the $\mathrm{Na} / \mathrm{K}$-ATPase, a marker of the plasma membrane, was mainly localised to the plasma membrane fraction, whereas the dihydropyridine receptor (DHPr), a transverse tubule $\mathrm{Ca}^{2+}$ channel, was mostly recovered in the TT, triads and SR fractions (Fig.4). We found both $e$ NOS and $n$ NOS in the CSM and they were mainly, if not entirely, associated with the plasma membrane. Neither enzymes could be detected in the triads or SR fractions.

Compared with control rats, $e$ NOS protein abundance was greatly reduced in CSM and purified plasma membrane fractions but not in TT isolated from muscle of 1-week diabetic animals (Fig. 5). The contents of $n$ NOS protein were not decreased, however, in CSM or plasma membrane fractions of the same muscles (Fig. 5), as previously observed in total homogenates of 1-week diabetic rats (Fig. 3). Content of $n$ NOS in the TT was below detection limits.

Recent studies indicate that both $n$ NOS and $e$ NOS associate with the caveolae in skeletal muscle and endothelial cells [24, 25, 28-31]. It has been postulated that direct binding of $e$ NOS and $n$ NOS on the scaffolding domains of caveolins inhibit enzymatic activity in a $\mathrm{Ca}^{2+}$-calmodulin-reversible fashion [24, 28, 29]. It was therefore possible that an increased expression of caveolin-1 in endothelial cells or the muscle-specific caveolin-3 isoform or both in myocytes, or an abnormally high interaction of the caveolins with NOS enzymes, are playing a part in the down-regulated
A
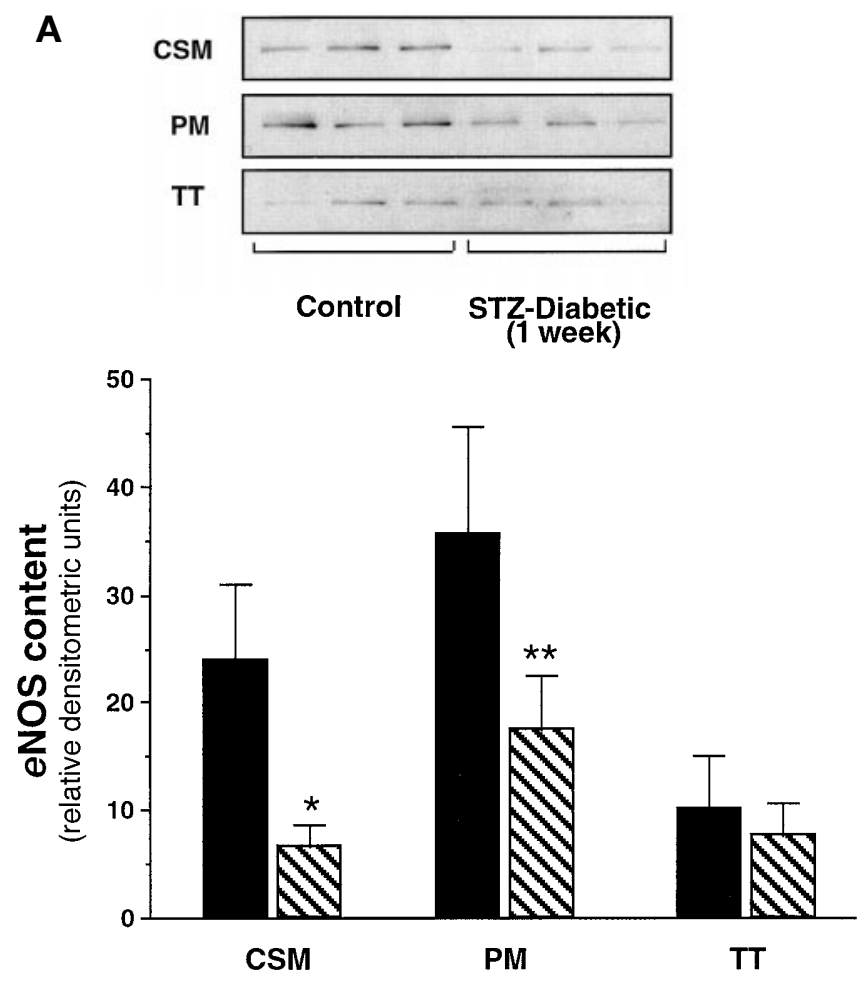

B
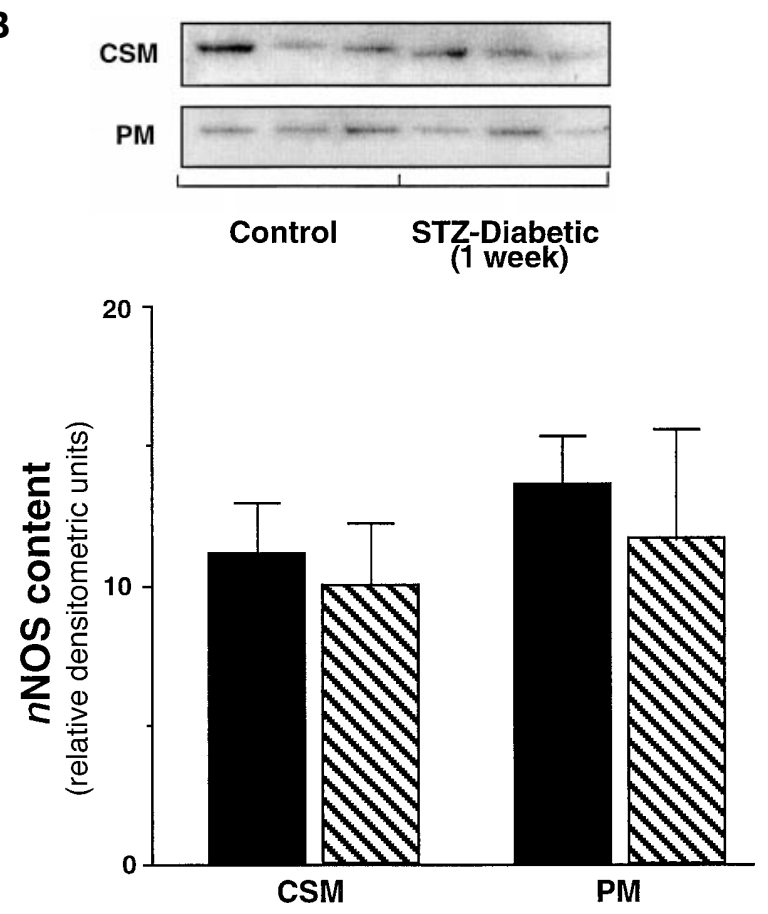

Fig. 5A, B. Effects of STZ-diabetes on (A) $e$ NOS and (B) $n$ NOS protein contents in crude surface membranes (CSM), plasma membranes (PM) and transverse tubules (TT) isolated from muscles of control and 1-week STZ-diabetic rats. Membrane proteins $(10 \mu \mathrm{g})$ were used for western blot analysis as described in Fig. 4. Upper gels show representative western blots with different rats in each experimental group. Bottom graphs represent means \pm SEM of three to five subcellular fractionation experiments with different animals. $* p<0.05 \mathrm{vs}$ control rats, ${ }^{* *} p=0.06, \boldsymbol{\square}$, control; $\mathbb{N}$, STZ-diabetic (1 week) 
A
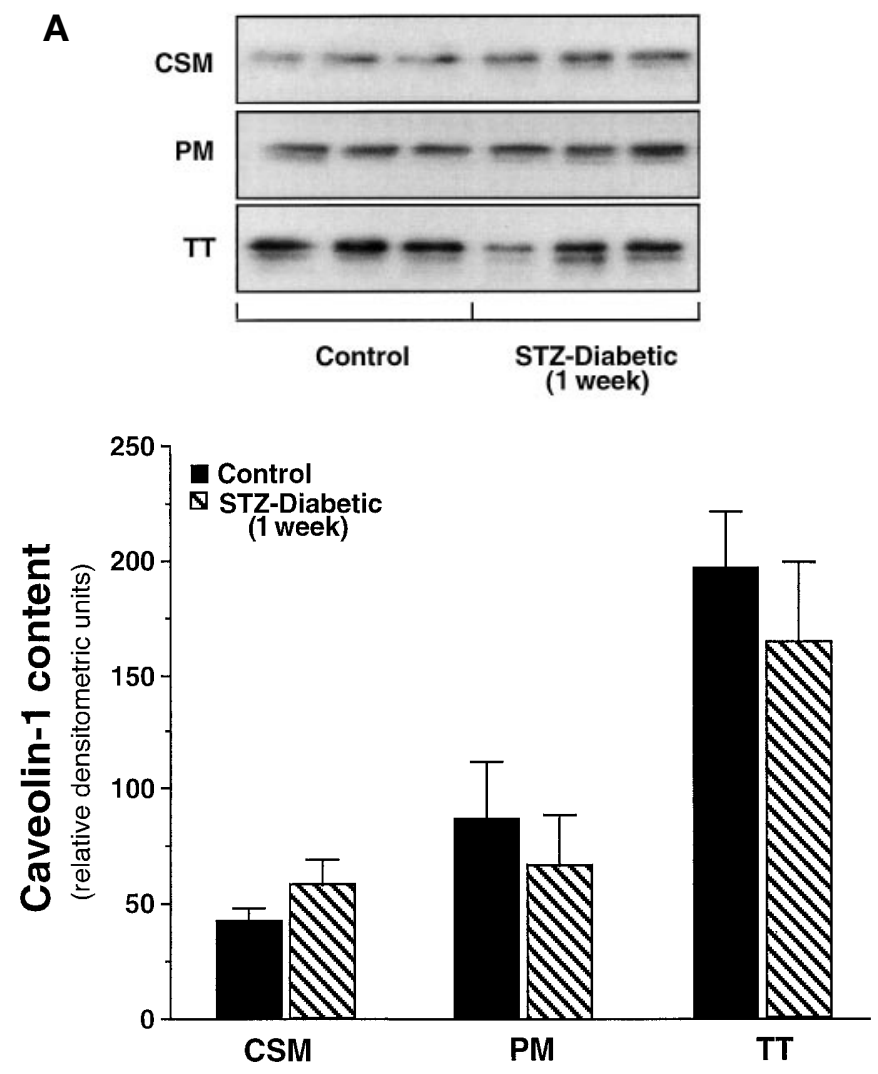

B
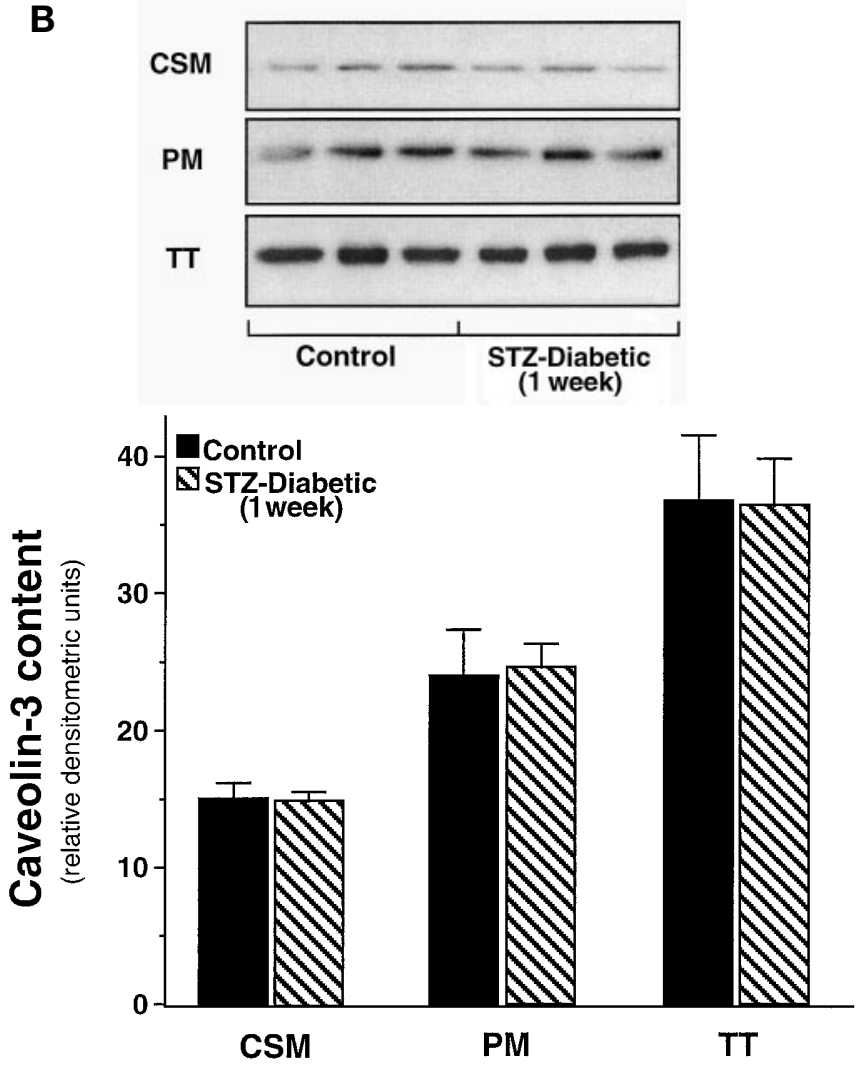

Fig. 6A, B. Caveolin-1 (A) and caveolin-3 (B) protein contents in crude surface membranes (CSM), plasma membranes (PM) and transverse tubules (TT) isolated from muscles of control and 1-week, STZ-diabetic rats. Membrane proteins $(10 \mu \mathrm{g})$ were used for western blot analysis using caveolin-1 polyclonal antibody (1:4000) or caveolin-3 monoclonal antibody (1:7500). Upper gels show representative western blots with different rats in each experimental group. Bottom graphs represent means \pm SEM of three to five subcellular fractionation experiments with different animals. No significant differences were observed between control and STZ-rats. $\square$, control; $\mathbb{N}$, STZ-diabetic (1 week)

NOS activity in muscle of 1 -week diabetic rats. To test this hypothesis, we first examined caveolin-1 and caveolin-3 protein concentrations in purified surface membrane fractions from muscle of control and STZ-rats (Fig. 6). In contrast to NOS enzymes, both caveolin-1 and caveolin-3 were mostly enriched in the TT and not in the plasma membrane fractions. The protein contents of either caveolin isoforms in the plasma membrane and TT fractions were, furthermore, not found to be affected by the diabetic state.

We next examined the interaction of caveolin isoforms with NOS enzymes by immunoprecipitation of caveolin-1 and caveolin-3 from muscle CSM fractions, followed by analysis of the immune complexes by SDS-PAGE and immunoblotting for $e$ NOS or $n$ NOS. We found $e$ NOS was associated with caveolin-1 in CSM fractions of skeletal muscle from both control and STZ-diabetic rats (Fig.7). The eNOScaveolin-1 interaction was not, however, found to be altered in skeletal muscle of diabetic rats (Fig. 7). In the same CSM fractions (data not shown) $n$ NOS was not immunoprecipitated by caveolin- 1 antibodies. We also examined whether $n$ NOS interacted with caveolin-3 in muscles of control and diabetic rats (Fig. 7). Caveolin-3 was immunoprecipitated from CSM fractions isolated from muscles of both control and diabetic rats but we could not detect $n$ NOS (Fig. 7) or $e$ NOS (data not shown) association with this muscle-specific caveolin isoform. Neither caveolin-1 nor caveolin-3 were immunoprecipitated when CSM samples were incubated with protein A Sepharose beads alone or when irrelevant antibodies (rabbit pre-immune serum or mouse $\mathrm{IgG}$ ) were used in place of caveolin antibodies (data not shown).

\section{Discussion}

It is well documented that impaired glucose metabolism and endothelial dysfunction are hallmarks of Type I diabetes. Skeletal muscle is the main site of postabsorptive glucose disposal and a major target of insulin action both on glucose uptake and blood flow. It is therefore critical to identify the defects be- 


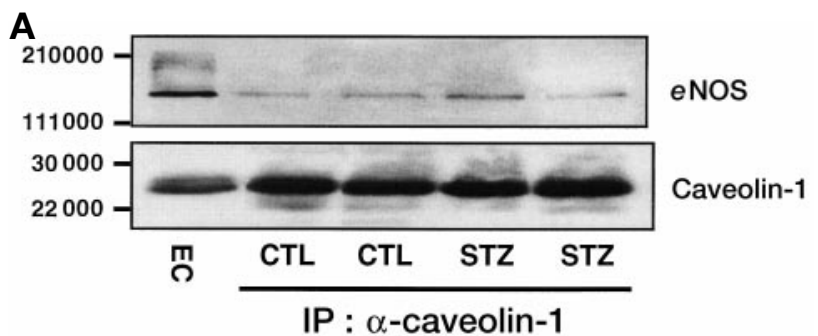

B

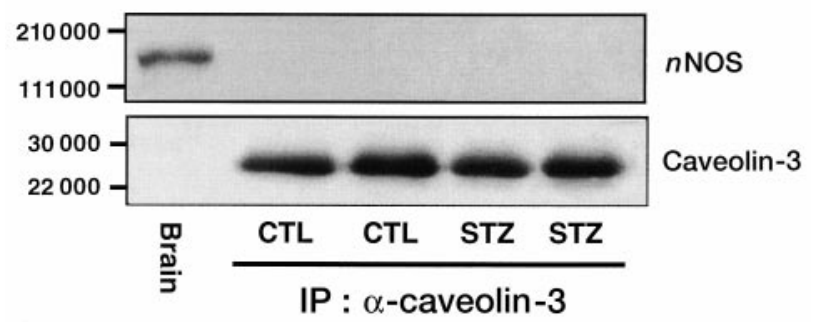

C

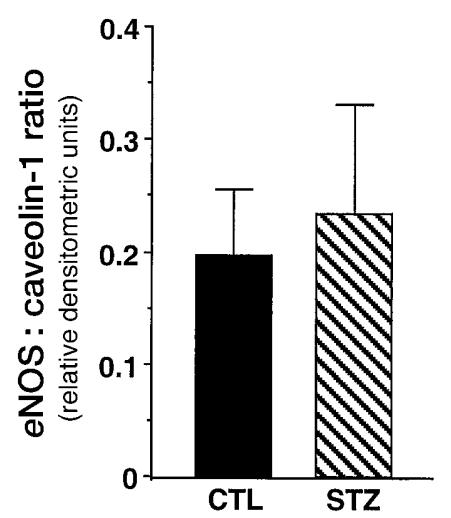

Fig. 7A-C. Interaction between caveolins and NOS enzymes in skeletal muscle of control and STZ-diabetic rats. CSM fractions were isolated from muscle of control and diabetic rats and caveolin-1 (A) and caveolin-3 (B) were immunoprecipitated. (C) Bars represent means \pm SEM of five immunoprecipitations with CSM membranes isolated from different animals. The immunoprecipitates were subjected to SDS-PAGE for western blot analysis of caveolins and NOS enzymes. Brain or endothelial cell extracts (EC, from Transduction Labs) were used as positive controls for $n$ NOS and $e$ NOS immunoreactive bands, respectively. Molecular weight standards (in $\mathbf{M}_{\mathrm{r}}$ ) are shown on the left. IP = immunoprecipitation, $\mathrm{CTL}=$ control

hind the development of impaired muscle glucose utilisation and vascular function in diabetes. Our study shows that NOS activity is considerably impaired in skeletal muscle of STZ-diabetic rats, suggesting a reduced capacity for NO production. The citrulline assay used in this study to assess NOS activity reflects the capacity of muscle NOS enzymes to synthesise NO under optimal conditions in terms of substrate (L-arginine) and cofactor $\left(\mathrm{BH}_{4}, \mathrm{Ca}^{2+}\right.$, calmodulin) concentrations in vitro. In vivo, however, it is possible that local concentrations of L-arginine or cofactors or both are reduced to subnormal levels in the muscle vascular endothelium, as previously reported for aortic rings of diabetic animals $[32,33]$. It is therefore possible that muscle NO production in STZ-diabetic rats is further decreased by the lack of optimal concentrations of these factors in vivo. Additional mechanisms such as increased destruction of the released $\mathrm{NO}$ by reactive oxygen species or resistance of the vascular smooth muscle cells to NO production could also contribute to endothelial dysfunction in muscle of diabetic rats $[6,10]$.

Our data further show that a reduced abundance of both $e$ NOS and $n$ NOS proteins is involved in the impaired NOS activity in skeletal muscle of diabetic rats. We found that the reduction in NOS activity in muscle of diabetic rats could mostly be explained by the down-regulation of $e$ NOS and $n$ NOS proteins in the tissue. Although the abundance of both NOS isoforms were found to be decreased in muscle of STZrats, the time of appearance of these alterations was different. After 1 week of diabetes $e$ NOS was significantly reduced whereas $n$ NOS protein concentrations were only affected after the second week. The earlier onset of $e$ NOS alteration in muscle of diabetic animals was also confirmed in purified plasma membranes, where NOS enzymes are more concentrated. On the other hand, neither $e$ NOS nor $n$ NOS transcript expression was affected by diabetes. This indicates that the reduced expression of $e$ NOS and $n$ NOS proteins in muscle of STZ-rats occurs at a post-transcriptional step, possibly through changes in translation efficiency or alterations in protein stability or both.

The reduced expression of NOS enzymes in skeletal muscle of diabetic rats could explain the impaired haemodynamic responses to NO-dependent vasodilators such as insulin $[2,34]$ and bradykinin [9] in the muscle vascular bed of people with Type I diabetes or STZ-rats, respectively. This defect could be selective for skeletal muscle vascular beds as the vasodilator responses to bradykinin was not altered in renal or mesenteric beds of STZ-diabetic rats, even 4 weeks after diabetes was induced [9]. Predominantly, $e$ NOS is found in the vascular endothelial cells in skeletal muscle. Whereas one report suggests that $e$ NOS is also expressed in muscle cells [27], most studies failed to detect $e$ NOS in these cells by immunocytochemistry $[25,35,36]$, thus suggesting that the impaired $e$ NOS expression in diabetic rats is mainly localised to the endothelial cells of the muscle vasculature. Because vascular NO production is important for the stimulatory action of insulin on skeletal muscle glucose uptake in vivo [17], the present data suggest that impaired muscle NOS activity is responsible, at least in part, for the lack of insulin-mediated glucose disposal in skeletal muscle of diabetic rats [5].

The biological function of $n$ NOS in skeletal muscle fibres is still not fully understood. It has been previously shown that $n$ NOS is concentrated at the neuromuscular junctions in the muscle spindles and the sarcolemmal membrane of fast-twitch muscle fibres $[12,26,37,38]$. Based on this localisation, it has been 
suggested that $n$ NOS-dependent NO release is involved in the regulation of synaptic actions of both intrafusal and extrafusal muscle fibres $[13,37,38]$ as well as in the direct modulation of contractile function [26]. Down-regulation of $n$ NOS in muscle cells and at the neuromuscular junction could thus be responsible for the long-term impairment in muscle contractile properties in the pathogenesis of diabetic neuromyopathy. Supporting this hypothesis is the recent finding that long-term diabetes impairs contractile function by affecting presynaptic control at the neuromuscular junction as well as at the muscle cells [19]. There is also evidence that diabetes can directly impair the contractile/regulatory system of a subpopulation of fast-twitch fibres [18, 39]. It is interesting to note, in this regard, that $n$ NOS is enriched in fasttwitch compared with slow-twitch fibres $[12,26]$. The decreased $n$ NOS protein content in muscle of diabetic rats could also be involved in the development of endothelial dysfunction in that tissue. A recent study suggests that $n$ NOS could also be located in capillaries of skeletal muscle and thus contribute to NO production in the vasculature [25].

Previous studies have shown that interaction of caveolins with NOS enzymes is increased in disease states associated with impaired NOS activity such as Duchenne muscular dystrophy and hypercholesterolaemia $[21,40]$. Because direct binding of $e$ NOS and $n$ NOS on the scaffolding domains of caveolins inhibits enzymatic activity [30, 41], it was of interest to test for possible alterations of $e$ NOS and $n$ NOS binding to skeletal muscle caveolins in diabetes. Caveolin-1 has been shown to be expressed in skeletal muscle capillaries whereas caveolin-3 is found in the myofibres [25]. We found, however, no evidence of increased expression or altered interaction of caveolins with NOS enzymes in muscle of STZ-diabetic rats. Unlike a previous study where $n$ NOS was shown to coimmunoprecipitate with caveolin-3 in skeletal muscle [30], we could not detect any association of these two proteins in our study. Caveolin-3 immunoprecipitation was done in the presence of several different detergents [octylglucoside, Triton X-100, or 3-[(3-cholamidopropyl)-dimethylammonio]-1-propanesulphonate (CHAPS)] with similar results (data not shown). The lack of detectable $n$ NOS-caveolin-3 interaction cannot be explained by the limit of detection of $n$ NOS or $e$ NOS by immunoblotting because caveolin-3 was quantifiably immunoprecipitated from up to $400 \mu \mathrm{g}$ of the CSM fraction and NOS enzymes can be readily detected from $10 \mu \mathrm{g}$ of CSM membranes. One possible explanation is that in the previous study [30] caveolin-3 was immunoprecipitated from total muscle homogenates whereas we have used semi-purified CSM fractions as starting material. It is possible that the interaction between $n$ NOS and caveolin-3 is specifically localised to some cellular compartments (e.g. cytoskeletal elements) not isolated by our fractionation procedure.
Both the duration and the severity of the diabetic state are important factors to consider when investigating the pathogenesis of diabetes. There is evidence, for example, that NO-mediated, endothelium-dependent vasodilatation can be either enhanced, unaffected or impaired depending on the stages of the disease $[7,8]$. It was therefore considered important in this study to assess muscle NOS activity and NOS expression during the progression of diabetes. Impaired NOS activity and $e$ NOS protein expression were already observed 1 week after experimental induction of diabetes and they worsened with the duration of the disease. This suggests that reduced NO production is an early onset impairment in diabetic muscle and not simply the consequence of pathomorphological changes that occur in later stages of the disease.

Subcellular fractionation experiments showed that $n$ NOS is predominantly localised or associated with the plasma membrane in rat skeletal muscle. These results are in agreement with previous studies [12, $25,26,42,43]$. It was recently reported that $n$ NOS is located in the SR of cardiac muscle where it could modulate $\mathrm{SR} \mathrm{Ca}^{2+}$ active transport [44]. It is not, however, found in SR vesicles isolated from skeletal muscle [44] and our subcellular fractionation experiments clearly show that $n$ NOS is localised neither to SR nor to triadic membranes. Whereas $e$ NOS was located both in the plasma membrane-enriched and TT-enriched vesicles in rat skeletal muscle, only the former surface component was found to have a reduced $e$ NOS content in muscle of STZ-rats. Since $e$ NOS is mostly located in the endothelial cells, it could, however, be suggested that plasma membrane vesicles from endothelial cells were recovered in the plasma membrane fraction after fractionation of the muscle tissue. The presence of the $\alpha 1$-subunit of the $\mathrm{Na} / \mathrm{K}$ ATPase in this fraction is consistent with the fact that this subunit is concentrated in the plasma membrane in endothelial cells [45].

This study shows that skeletal muscle NOS activity is impaired during the progression of STZ-induced diabetes. The reduced NOS activity is mostly explained by a decreased abundance of both $n \mathrm{NOS}$ and $e$ NOS proteins but is not related to alterations in either caveolin expression or their interaction with NOSs. Post-transcriptional mechanisms are responsible for the lack of NOS enzymes protein expression in muscle of diabetic rats.

Acknowledgements. We wish to thank Dr C.H. Côté and Dr R. Tatchum-Talom for critical reading of the manuscript. This work was supported by a grant from the Canadian Medical Research Council (A. Marette). A. Marette was supported by scholarships from the Canadian Medical Research Council and the Quebec Funds for Health Research (FRSQ). M. Perreault and L. Dombrowski were supported by studentships from the Quebec Diabetes Association and from the FCARFRSQ (a fund which supports researchers and Quebec Funds for Health Research), respectively. 


\section{References}

1. Makimattila S, Virkamaki A, Malmstrom R, Utriainen T, Yki-Jarvinen H (1996) Insulin resistance in type I diabetes mellitus: a major role for reduced glucose extraction. J Clin Endocrinol Metab 81: 707-712

2. Baron AD, Laakso M, Brechtel G, Edelman SV (1991) Mechanism of insulin resistance in insulin-dependent diabetes mellitus: a major role for reduced skeletal muscle blood flow. J Clin Endocrinol Metab 73: 637-643

3. Folli F, Saad MJA, Backer JM, Kahn CR (1993) Regulation of phosphatidylinositol 3-kinase activity in liver and muscle of animal models of insulin-resistant and insulin-deficient diabetes-mellitus. J Clin Invest 92: 1787-1794

4. Dombrowski L, Marette A (1995) Marked depletion of GLUT4 glucose transporters in transverse tubules of skeletal muscle from streptozotocin-induced diabetic rats. FEBS Lett 374: 43-47

5. Dombrowski L, Roy D, Marette A (1998) Selective impairment in GLUT4 translocation to transverse tubules in skeletal muscle of streptozotocin-induced diabetic rats. Diabetes 47: 5-12

6. Pieper GM (1998) Review of alterations in endothelial nitric oxide production in diabetes: protective role of arginine on endothelial dysfunction. Hypertension 31: 1047-1060

7. Pieper GM (1999) Enhanced, unaltered and impaired nitric oxide-mediated endothelium-dependent relaxation in experimental diabetes mellitus: importance of disease duration. Diabetologia 42: 204-213

8. Sobrevia L, Mann GE (1997) Dysfunction of the endothelial nitric oxide signalling pathway in diabetes and hyperglycaemia. Exp Physiol 82: 423-452

9. Kiff RJ, Gardiner SM, Compton AM, Bennett T (1991) Selective impairment of hindquarters vasodilator responses to bradykinin in conscious Wistar rats with streptozotocininduced diabetes mellitus. Br J Pharmacol 103: 1357-1362

10. Harrison DG (1997) Cellular and molecular mechanisms of endothelial cell dysfunction. J Clin Invest 100: 2153-2157

11. Rubinstein I, Abassi Z, Coleman R, Milman F, Winaver J, Better OS (1998) Involvement of nitric oxide system in experimental muscle crush injury. J Clin Invest 101: 1325-1333

12. Kapur S, Bedard S, Marcotte B, Cote CH, Marette A (1997) Expression of nitric oxide synthase in skeletal muscle: a novel role for nitric oxide as a modulator of insulin action. Diabetes 46: 1691-1700

13. Christopherson KS, Bredt DS (1997) Nitric oxide in excitable tissues: physiological roles and disease. J Clin Invest 100: 2424-2429

14. Baron AD (1994) Hemodynamic actions of insulin. Am J Physiol 267:E187-E202

15. Baron AD, Steinberg HO, Chaker H, Leaming R, Johnson A, Brechtel G (1995) Insulin-mediated skeletal muscle vasodilation contributes to both insulin sensitivity and responsiveness in lean humans. J Clin Invest 96: 786-792

16. Baron AD (1996) The coupling of glucose metabolism and perfusion in human skeletal muscle. The potential role of Endothelium-derived nitric oxide. Diabetes 45[Suppl 1]:S105-S109

17. Roy D, Perreault M, Marette A (1998) Insulin stimulation of glucose uptake in skeletal muscles and adipose tissues in vivo is NO dependent. Am J Physiol 274:E692-E699

18. Stephenson GM, O'Callaghan A, Stephenson DG (1994) Single-fiber study of contractile and biochemical properties of skeletal muscles in streptozotocin-induced diabetic rats. Diabetes 43: 622-628
19. Fahim MA, el-Sabban F, Davidson N (1998) Muscle contractility decrement and correlated morphology during the pathogenesis of streptozotocin-diabetic mice. Anat Rec 251: 240-244

20. Dombrowski L, Roy D, Marcotte B, Marette A (1996) A new procedure for the isolation of plasma membranes, $\mathrm{T}$ tubules, and internal membranes from skeletal muscle. Am J Physiol 270:E667-E676

21. Feron O, Dessy C, Moniotte S, Desager JP, Balligand JL (1999) Hypercholesterolemia decreases nitric oxide production by promoting the interaction of caveolin and endothelial nitric oxide synthase. J Clin Invest 103: 897-905

22. Laemmli UK (1970) Cleavage of structural proteins during the assembly of the head of bacteriophage T4. Nature 227: 680-685

23. Chomczynski P, Sacchi N (1987) Single-step method of RNA isolation by acidic guanidium thiocyanate-phenolchloroform extraction. Anal Biochem 162: 156-159

24. Michel T, Feron O (1997) Nitric oxide synthases: which, where, how, and why? J Clin Invest 100: 2146-2152

25. Segal SS, Brett SE, Sessa WC (1999) Codistribution of NOS and caveolin throughout peripheral vasculature and skeletal muscle of hamsters. Am J Physiol 277: H1167-H1177

26. Kobzik L, Reid MB, Bredt DS, Stamler JS (1994) Nitric oxide in skeletal muscle. Nature 372: 546-548

27. Kobzik L, Stringer B, Balligand JL, Reid MB, Stamler JS (1995) Endothelial type nitric oxide synthase in skeletal muscle fibers - mitochondrial relationships. Biochem Biophys Res Commun 211: 375-381

28. Michel JB, Feron O, Sacks D, Michel T (1997) Reciprocal regulation of endothelial nitric-oxide synthase by $\mathrm{Ca}^{2+}$ calmodulin and caveolin. J Biol Chem 272: 15583-15586

29. Michel JB, Feron O, Sase K, Prabhakar P, Michel T (1997) Caveolin versus calmodulin. Counterbalancing allosteric modulators of endothelial nitric oxide synthase. J Biol Chem 272: 25907-25912

30. Venema VJ, Ju H, Zou R, Venema RC (1997) Interaction of neuronal nitric-oxide synthase with caveolin-3 in skeletal muscle. Identification of a novel caveolin scaffolding/inhibitory domain. J Biol Chem 272: 28187-28190

31. Garcia-Cardena G, Martasek P, Masters BS et al. (1997) Dissecting the interaction between nitric oxide synthase (NOS) and caveolin. Functional significance of the nos caveolin binding domain in vivo. J Biol Chem 272: 25437-25440

32. Pieper GM, Dondlinger LA (1997) Plasma and vascular tissue arginine are decreased in diabetes: acute arginine supplementation restores endothelium-dependent relaxation by augmenting cGMP production. J Pharmacol Exp Ther 283: 684-691

33. Pieper GM (1997) Acute amelioration of diabetic endothelial dysfunction with a derivative of the nitric oxide synthase cofactor, tetrahydrobiopterin. J Cardiovasc Pharmacol 29: 8-15

34. Steinberg HO, Brechtel G, Johnson A, Fineberg N, Baron AD (1994) Insulin-mediated skeletal muscle vasodilation is nitric oxide dependent. A novel action of insulin to increase nitric oxide release. J Clin Invest 94: 1172-1179

35. El Dwairi Q, Guo Y, Comtois A et al. (1998) Ontogenesis of nitric oxide synthases in the ventilatory muscles. Am J Respir Cell Mol Biol 18: 844-852

36. Frandsen U, Lopez-Figueroa M, Hellsten Y (1996) Localization of nitric oxide synthase in human skeletal muscle. Biochem Biophys Res Commun 227: 88-93

37. Chao DS, Silvagno F, Xia H, Cornwell TL, Lincoln TM, Bredt DS (1997) Nitric oxide synthase and cyclic GMP-de- 
pendent protein kinase concentrated at the neuromuscular endplate. Neuroscience 76: 665-672

38. Kusner LL, Kaminski HJ (1996) Nitric oxide synthase is concentrated at the skeletal muscle endplate. Brain Res 730: 238-242

39. Paulus SF, Grossie J (1983) Skeletal muscle in alloxan diabetes. A comparison of isometric contractions in fast and slow muscle. Diabetes 32: 1035-1039

40. Vaghy PL, Fang J, Wu W, Vaghy LP (1998) Increased caveolin-3 levels in mdx mouse muscles. FEBS Lett 431: 125-127

41. Feron O, Belhassen L, Kobzik L, Smith TW, Kelly RA, Michel T (1996) Endothelial nitric oxide synthase targeting to caveolae. Specific interactions with caveolin isoforms in cardiac myocytes and endothelial cells. J Biol Chem 271: 22810-22814
42. Grozdanovic Z, Gosztonyi G, Gossrau R (1996) Nitric oxide synthase I (NOS-I) is deficient in the sarcolemma of striated muscle fibers in patients with Duchenne muscular dystrophy, suggesting an association with dystrophin. Acta Histochem 98: 61-69

43. Brenman JE, Chao DS, Xia HH, Aldape K, Bredt DS (1995) Nitric-oxide synthase complexed with dystrophin and absent from skeletal-muscle sarcolemma in duchenne muscular-dystrophy. Cell 82: 743-752

44. Xu KY, Huso DL, Dawson TM, Bredt DS, Becker LC (1999) Nitric oxide synthase in cardiac sarcoplasmic reticulum. Proc Natl Acad Sci USA 96: 657-662

45. Moser TL, Stack MS, Asplin I et al. (1999) Angiostatin binds ATP synthase on the surface of human endothelial cells. Proc Natl Acad Sci USA 96: 2811-2816 